Document downloaded from:

http://hdl.handle.net/10251/66293

This paper must be cited as:

Santamaría Pérez, D.; Errandonea, D.; Gomis, O.; Sans Tresserras, JÁ; Pereira, ALJ.; Manjón Herrera, FJ.; Popescu, C.... (2015). Crystal structure of sinhalite MgAlBO4 under high pressure. Journal of Physical Chemistry C. 119(12):6777-6784. doi:10.1021/jp512131e.

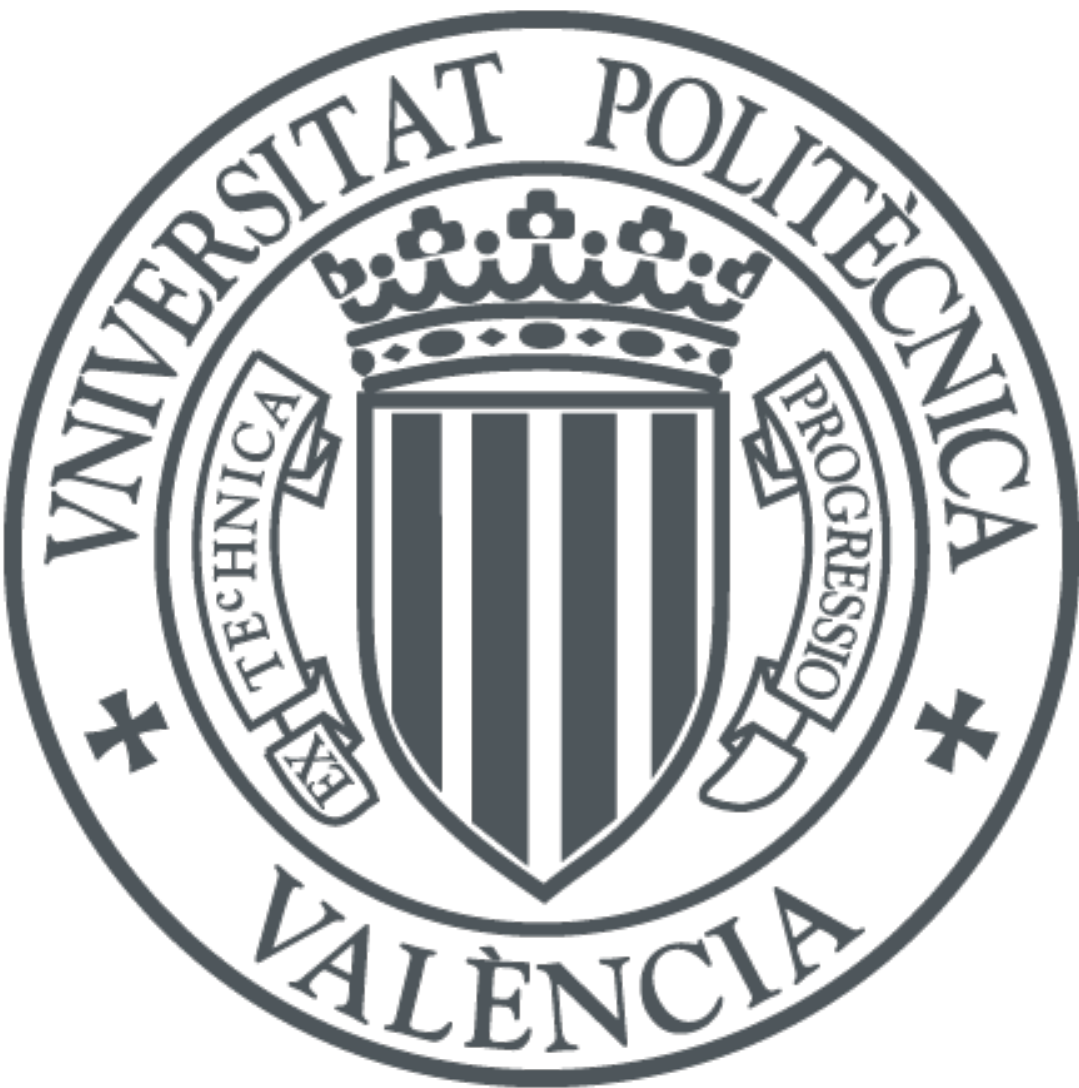

The final publication is available at

http://dx.doi.org/10.1021/jp512131e

Copyright American Chemical Society

Additional Information

This document is the Accepted Manuscript version of a Published Work that appeared in final form in

Journal of Physical Chemistry C, copyright (C) American Chemical Society after peer review and technical editing by the publisher. To access the final edited and published work see http://dx.doi.org/10.1021/jp512131e 


\title{
The Crystal Structure of Sinhalite $\mathrm{MgAlBO}_{4}$ under High Pressure
}

\author{
D. Santamaria-Perez1,2,*, D. Errandonea², O. Gomis³, J.A. Sans 4 , A.L.J. Pereira4, F.J. Manjon4, C.
} Popescu 5 , P. Rodriguez-Hernandez ${ }^{6}$, A. Muñoz ${ }^{6}$.

${ }^{1}$ Earth Sciences Department, University College London, Gower Street, WC1E 6BT, London (UK)

${ }^{2}$ Departamento de Física Aplicada-ICMUV, MALTA Consolider Team, Universidad de Valencia, C/Dr. Moliner

50, Burjassot, 46100 Valencia (Spain)

${ }^{3}$ Centro de Tecnologías Físicas: Acústica, Materiales y Astrofisica, MALTA Consolider Team, Universitat Politècnica de València, Camino de Vera s/n, 46022 València (Spain)

4 Instituto de Diseño para la Fabricación y Producción Automatizada, MALTA Consolider Team, Universitat Politècnica de València, Camino de Vera s/n, 46022 València (Spain)

${ }^{5}$ CELLS-ALBA Synchrotron Light Facility, 08290 Cerdanyola del Vallés, Barcelona (Spain)

${ }^{6}$ Departamento de Física, Instituto Univ. de Materiales y Nanotecnología, MALTA Consolider Team, Universidad de La Laguna, La Laguna, Tenerife (Spain)

\section{Abstract}

We report on high-pressure angle-dispersive x-ray diffraction data up to $27 \mathrm{GPa}$ for natural $\mathrm{MgAlBO}_{4}$ sinhalite mineral and ab initio total energy calculations. The experimental bulk modulus of sinhalite is $\mathrm{B}_{0}$ $=171(3) \mathrm{GPa}$ with a first-pressure derivative of $\mathrm{B}_{0}{ }^{\prime}=4.2(3)$. A comparison with other olivine-type compounds shows that the value for $\mathrm{B}_{0}$ is $27 \%$ larger than that of $\mathrm{Mg}_{2} \mathrm{SiO}_{4}$ forsterite and $29 \%$ smaller than that of $\mathrm{Al}_{2} \mathrm{BeO}_{4}$ chrysoberyl. These differences are interpreted, on the basis of our ab initio calculations, in terms of the relative incompressibility of $\mathrm{Al}-\mathrm{O}$ bonds in $\mathrm{AlO}_{6}$ octahedra (with a calculated bulk modulus of $250(1) \mathrm{GPa}$ ) as compared to $\mathrm{Mg}-\mathrm{O}$ bonds in $\mathrm{MgO}_{6}$ octahedra (with a calculated bulk modulus of $130(1) \mathrm{GPa}$ ). The spatial cation distribution in the Pbnm orthorhombic unit-cell and different polyhedral compressibilities entail a strong anisotropic compression comparable to that of forsterite. The axial compressibilities are $1.06(2) \cdot 10^{-3}, 2.17(2) \cdot 10^{-3}$ and $1.30(3) \cdot 10^{-3} \mathrm{GPa}^{-1}$ for $a, b$ and $c$ axes, respectively. The crystal chemistry of sinhalite under compression is compared to that of other olivinelike compounds. Compressibility trends and possible high-pressure phases are discussed.

${ }^{*}$ Corresponding address email: d.santamaria-perez@ucl.ac.uk Phone: +34963543881 
Crystal structures of olivine-group minerals have been extensively studied because of the relevance of $(\mathrm{Mg}, \mathrm{Fe})_{2} \mathrm{SiO}_{4}$ silicates as major crustal and upper mantle minerals as well as the interest on their inherent crystal chemistry properties. A large number of compounds crystallize in the olivine-type structure, including silicates of the aforementioned forsterite-fayalite series $(\mathrm{Mg}$ and $\mathrm{Fe}$ as divalent cations) or formed by other divalent cations; e.g. $\mathrm{Ca}^{2+}$ or $\mathrm{Mn}^{2+}$, and also non-silicate compounds such as chrysoberyl, $\mathrm{Al}_{2} \mathrm{BeO}_{4}$, or sinhalite, $\mathrm{MgAlBO}_{4}$. The olivine-type $\mathrm{M}(1) \mathrm{M}(2) \mathrm{TO}_{4}$ structure is described within the orthorhombic Pbnm space group (SG, No. 62) with 4 formula units per cell. It consists of a distorted hexagonal close-packed arrangement of oxygen atoms in which half of the octahedral sites are occupied by $M(1)$ and $M(2)$ cations and one eighth of the tetrahedral sites contain $T$ atoms.

The structure of mineral sinhalite, $\mathrm{MgAlBO}_{4}$, was reported from a natural sample ${ }^{1,2}$, but it was also synthesized under hydrothermal conditions ${ }^{3}$, at pressures ranging from 2 to $8 \mathrm{GPa}$ and temperatures of $1473 \mathrm{~K}$. Its structure (see Figures 1a-c) is defined by a $M(1)$ octahedral site (point symmetry -1) occupied by small and highly electronegative $\mathrm{Al}^{3^{+}}$cations, a $\mathrm{M}(2)$ octahedral site (point symmetry $\mathrm{m}$ ) occupied by large and less electronegative $\mathrm{Mg}^{2+}$ cations, and a $\mathrm{T}$ tetrahedral site (point symmetry $\mathrm{m}$ ) containing $\mathrm{B}$ atoms ${ }^{4}$. Both $\mathrm{AlO}_{6}$ and $\mathrm{MgO}_{6}$ octahedra are distorted and the $\mathrm{BO}_{4}$ tetrahedron has a skewed appearance with an abnormally long $\mathrm{B}-\mathrm{O}$ distance. Major structural features have been considered to be the edge-sharing octahedra zigzag chains running parallel to $c$ (Fig. 1a) and, in particular, the columns formed by the $\mathrm{M}(1)$ octahedra (in projection in Fig. 1c). An alternative description for this structure in terms of its cation subarray was proposed5,6. In this sense, the cationic framework of sinhalite can be considered as an orthorhombic distortion of the hexagonal $\mathrm{Ni}_{2} \mathrm{In}$-type structure with trigonal prisms formed by $\mathrm{Mg}$ and $\mathrm{Al}$ atoms centred by $\mathrm{B}$ atoms linked by face-sharing to form a corrugated-prismatic structure (see Figure 1d). The partial [MgAIB] substructure can also be regarded as a distortion of the $\mathrm{AlB}_{2}$-type structure in which irregular graphite-like layers formed by $\mathrm{B}$ and $\mathrm{Mg}$ atoms alternate with slightly distorted $3^{6}$ planar nets of $\mathrm{Al} \mathrm{atoms} \mathrm{s}^{6}$. We note here that structural analyses in terms of second-neighbour contacts have proven to be particularly useful in determining high pressure and temperature tendencies and polymorphism ${ }^{7-11}$.

As far as we know, no high pressure (HP) study on this mineral has been reported. Sinhalite, $\mathrm{MgAlBO}_{4}$, with both $\mathrm{Mg}-\mathrm{O}$ and $\mathrm{Al}-\mathrm{O}$ bonds constitutes the natural bridge between silicate olivines such as forsterite, $\mathrm{Mg}_{2} \mathrm{SiO}_{4}$, and chrysoberil, $\mathrm{Al}_{2} \mathrm{BeO}_{4}$, which contain only $\mathrm{Mg}-\mathrm{O}$ or Al-O bonds. Thus, sinhalite is particularly interesting for a compressibility study since, in many oxides and silicates, unit-cell volume is proportional to compressibility ${ }^{12}$. In particular, this mineral is expected to have one of the largest bulk 
moduli among olivines because of its small unit-cell volume when compared to other olivines. Moreover, its axial anisotropy would give insight into the pressure-induced distortion of compositionally different polyhedra. Therefore, the principal aims of this experimental and theoretical work are: (i) the determination of volume and axial compressibilities of sinhalite, (ii) the determination of polyhedral compressibilities, (iii) the understanding of pressure effects in the behaviour of the sinhalite crystalline structure; i.e. polyhedral distortions, and (iv) the comparison with other natural and synthetic olivines. For this purpose we carried out room-temperature angle-dispersive X-ray diffraction (XRD) measurements up to $27 \mathrm{GPa}$ and state-of-the-art ab initio total energy calculations, which provide an accurate description of the variation of bond distances and the polyhedral compressibilities with pressure.

\section{2.- Experimental details}

To perform powder XRD measurements, a natural $\mathrm{MgAlBO}_{4}$ crystal was crushed in a mortar with a pestle to obtain a micrometer-sized powder. XRD measurements at ambient conditions confirmed that our sample has an olivine-like structure. Energy dispersive X-ray spectroscopy (EDS) electronmicroprobe analyses of the sample were performed on a JEOL JSM6300 apparatus with an Oxford Instruments detector. Final chemical composition for $\mathrm{MgAlBO}_{4}$ was obtained by assuming stoichiometric borate and charge balancing against $\mathrm{BO}_{4}{ }^{5-}$, as reported elsewhere ${ }^{1,13}$. No traces of other elements apart from $\mathrm{Mg}, \mathrm{Al}, \mathrm{B}$ and $\mathrm{O}$ were found.

Two independent HP angle-dispersive XRD experiments were conducted at room temperature at the MSPD beamline ${ }^{14}$ of the ALBA Synchrotron Light Source with an incident monochromatic wavelength of $0.4246 \AA$ focused to $20 \times 20 \mu \mathrm{m}^{2}$. Experiment 1 was carried out up to $27 \mathrm{GPa}$. Measurements were performed in a membrane-type diamond-anvil cell (DAC) with diamond culets of $400 \mu \mathrm{m}$. Sinhalite powder was loaded in a $160 \mu \mathrm{m}$ diameter hole of a stainless-steel gasket preindented to a thickness of about $50 \mu \mathrm{m}$. A 4:1 methanol-ethanol mixture was used as the pressure-transmitting medium. Experiment 2, up to $14 \mathrm{GPa}$, was performed in a symmetric DAC with diamond culets of $500 \mu \mathrm{m}$ and a drilled rhenium gasket with a $200-\mu \mathrm{m}$ diameter hole. $\mathrm{MgAIBO}_{4}$ powder was loaded in the DAC using argon as the pressure transmitting medium. This latter run was stopped at $14 \mathrm{GPa}$ after a drastic deformation of the pressure chamber. In this study, pressure was determined using the ruby fluorescence technique ${ }^{15}$. In the second experiment, pressure calibration was also confirmed by the equation of state (EOS) of $\operatorname{Ar}^{16}$. 
XRD images covering a $2 \theta$ range up to $18^{\circ}$ were collected using a Rayonix SX165 CCD detector. Detector calibration, correction of distortion, and integration to conventional $2 \theta$-intensity data were carried out in both cases with the FIT2D software ${ }^{17}$. The indexing and refinement of the powder patterns were performed using the FULLPROF ${ }^{18}$ and POWDERCELL ${ }^{19}$ program packages.

\section{3.- Computational details}

$A b$ initio simulations were performed within the framework of the density functional theory (DFT) and the pseudopotential method as implemented in the Vienna ab initio simulation package (VASP) of which a detailed account can be found in Refs. 20, 21 and references therein. The exchange and correlation energy has been taken in the generalized gradient approximation (GGA) according to the Perdew-Burke-Ernzerhof (PBEsol) prescription for solids ${ }^{22}$. The projector augmented wave pseudopotential (PAW) scheme ${ }^{23}$ was adopted to take into account the full nodal character of the allelectron charge density distribution in the core region. The basis sets employed included plane waves up to a kinetic energy cutoff of $520 \mathrm{eV}$ to achieve highly converged results that ensure an accurate structural description.

In order to understand the compressibility of sinhalite and identify a potential HP phase, we have carried out first-principles calculations of the initial sinhalite (Pbnm, No. 62) structure and four potential HP phases, namely: wadsleyite-type (SG: Imma, No. 74), ringwoodite/spinel-type (SG: Fd-3m, No. 227), TIAISiO 4 -type (SG: $P 21 / n$, No. 14), and thenardite-type (SG: Fddd, No. 70). These four candidate structures were selected by empirical crystal chemical arguments, such as forsterite phase transitions at high pressures and temperatures ${ }^{24}$, and the behaviour under pressure of the cation subarrays in oxides ${ }^{6,7,10}$. Note that the olivine structure of sinhalite $\mathrm{MgAlBO}_{4}$ has two different $\mathrm{M}$ cations, $\mathrm{Mg}^{2+}$ and $\mathrm{Al}^{3+}$, compared to the olivine structure of forsterite, $\mathrm{Mg}_{2} \mathrm{SiO}_{4}$, with only $\mathrm{Mg}^{2+}$ cations. Thus, the simulation of the thenardite and spinel structures, with special high symmetry positions, could only be performed provided that these two structures are described in terms of some of their subgroups with less symmetry elements. Site splitting permits the occupancy by different type of atoms, in our case $\mathrm{Mg}$ and Al. In particular, thenardite was defined with the orthorhombic SG F222 (No. 22) structure, which allows to split the Wyckoff position 16e (occupied by the $M$ atoms in the Fddd space group) into two independent positions (8e and 8j) in the F222 phase. On the other hand, spinel (SG Fd-3m, Z = 8 and lattice parameter a) was simulated with the orthorhombic SG Imma $\left(Z=4, a^{\prime}=a / \sqrt{ } 2, b^{\prime}=a / \sqrt{ } 2\right.$, and $c^{\prime}=$ a) structure, which allows to split the Wyckoff position 16d (occupied with $M$ atoms in the cubic spinel structure, e.g. $\mathrm{Mg}_{2} \mathrm{SiO}_{4}$ ringwoodite) into two independent positions (4b and 4c) in the Imma phase 25 . 
132 For all the studied structures, dense special k-points samplings were used for the Brillouin zone integrations to obtain well converged energies and forces. At each selected volume, the structures were fully relaxed to their equilibrium configuration (forces on the atoms less than $0.004 \mathrm{eV} / \AA$ and deviation of the stress tensor from a diagonal hydrostatic form less than $1 \mathrm{Kbar})$. It is important to note that from DFT ab initio simulations, the theoretical pressure, $\mathrm{P}(\mathrm{V})$, is obtained at the same time as the total energy, $\mathrm{E}(\mathrm{V})$. Pressure, like other energy derivatives, is calculated from the stress tensor ${ }^{26}$.

\section{4.- Results and discussion}

\section{A. Structural properties of sinhalite under pressure.}

At room conditions, the XRD pattern of sinhalite corresponds to the orthorhombic olivine-like structure previously reported (SG Pbnm, No. 62), with similar lattice parameters: $a=4.3322(3) \AA, b=9.8762(8)$ $\AA$, and $c=5.6753(6) \AA\left(Z=4, V=242.86(2) \AA^{3}\right)$ to those given in the literature [3,4]. No new Bragg peaks indicative of a phase transition were observed in the XRD patterns up to $27 \mathrm{GPa}$ (see Fig. 2). The evolution of the unit-cell parameters (see Fig. 3) and volume (see Fig. 4) as a function of pressure and obtained by using with different pressure transmitting media present an excellent overall agreement among them and with our ab initio total-energy calculations. Hereafter, theoretical values will be denoted in parentheses. The lattice parameters of the orthorhombic unit cell $(a, b$, and $c)$ vary smoothly with increasing pressure, which also supports the absence of phase transitions in this pressure range. The absolute contractions for $a-, b$-, and $c$-axis between room pressure and $27 \mathrm{GPa}$ are $0.1227,0.5676$, and $0.1833 \AA$, respectively. Experimental (theoretical) axial linear compressibilities for sinhalite are: $\beta_{a}=1.06(2) \cdot 10^{-3}\left(1.19 \cdot 10^{-3}\right), \beta_{b}=2.17(2) \cdot 10^{-3}\left(2.30 \cdot 10^{-3}\right)$, and $\beta_{c}=1.30(3) \cdot 10^{-3}$ $\left(1.46 \cdot 10^{-3}\right) \mathrm{GPa}^{-1}$ and indicate strong axial anisotropy. Calculated axial compression ratios defined as $\beta_{a}{ }^{\text {rat }}=\beta_{a} / \beta_{a}, \beta_{b}$ rat $=\beta_{b} / \beta_{a}$, and $\beta_{c}{ }^{\text {rat }}=\beta_{c} / \beta_{a}$ are 1.00:2.05:1.23 (1.00:1.93:1.23), respectively. These results clearly indicate that there is a strong axial anisotropy in sinhalite with the $b$ axis being almost twice as compressible as the $a$ and $c$ axis. A least-squares fit of unit-cell volume data to a $3^{\text {rd }}$ order Birch-Murnaghan (BM) EOS 27 yields a zero-pressure volume $V_{0}=242.8(1) \AA^{3}$, a bulk modulus of $B_{0}=$ 171(3) $\mathrm{GPa}$ and its first-pressure derivative $B^{\prime}{ }_{0}=4.2(3)$. These values are consistent with a fit of experimental data to a $2^{\text {nd }}$ order BM EOS, i.e., with $B_{0}{ }^{\prime}=4$ (fixed), which yields $V_{0}=242.7(1) \AA^{3}$ and $B_{0}$ $=173(1) \mathrm{GPa}$. Notably, these experimental results compare very well with those obtained from theoretical calculations: $V_{0}=244.16(1) \AA^{3}, B_{0}=167.64(1) \mathrm{GPa}$ and $B_{0}^{\prime}=4.51(1)$. 
are not accurate, avoiding full structural refinements for sinhalite in the case of our experiment 1. In experiment 2 which presents more uniform diffraction rings but still spotty, and where Ar is used as pressure transmitting medium, the atomic positions were tentatively obtained at different pressures by Rietveld refinements. We found that the pressure changes in the atomic positions were comparable with experimental uncertainties. Therefore no reliable information on the evolution of the atomic positions under pressure could be obtained from our experimental data. For this reason and taking into account the good agreement found between experimental and theoretical data in (i) lattice parameters and atomic positions at ambient conditions (see Table 1) and (ii) the unit-cell compressibility data, we use data from our ab initio total-energy simulations to study the variation of bond distances and polyhedral compressibilities with pressure. Polyhedral volumes for $\mathrm{MgAlBO}_{4}$ vary smoothly with pressure (see Fig. 5 and Table 2) and give the following bulk moduli: 250(1), 130(1) and 409(1) GPa for the $M(1-A I), M(2-M g)$ and $T(B)$ sites, respectively, by using a $2^{\text {nd }}$ order BM EOS. Table 2 also summarizes the quadratic elongation and bond angle variance 28 in the different polyhedra of sinhalite at different pressures, since these two parameters can provide a rough idea of the distortion and compressibility mechanisms of the different polyhedral units as a function of pressure. It can be observed that both parameters decrease slightly with pressure in all polyhedra, in particular at a greater rate for $\mathrm{MgO}_{6}$; thus showing a progressive reduction of the distortion of all polyhedral units with increasing pressure.

Bulk moduli, axial compressibilities and axial compression ratios of different olivine-type compounds are summarized in Table 3 for comparison purposes $29-33$. The cause for the observed strong anisotropic compressibility in sinhalite and most olivine-type compounds is related to the spatial cation distribution among the $M(1), M(2)$ and T sites as well as the different compressibility of the polyhedral units in the Pbnm orthorhombic unit-cell. A deep understanding of the axial compressibilities of sinhalite and other olivines can be only achieved through a detailed examination of its structure ${ }^{34-36}$. Lumpkin and Ribbe ${ }^{36}$ reported regression equations that relate the cell dimensions of O-bearing olivines with the size of cations occupying the different octahedral and tetrahedral sites. They showed that: (i) the a-axis is mainly affected by the nature of $\mathrm{M}(1)$ and $\mathrm{T}$ atoms, (ii) that the $b$ dimension is primarily sensitive to cations occupying $\mathrm{M}(2)$ octahedra, and (iii) that the length of the $c$-axis depends to a greater extent on the size of the $M(1)$ and $M(2)$ cations. Note, however, that this analysis in terms of cation-centred polyhedra should be considered within a wider perspective that also includes the study of the metallic framework existing in the olivine structure. Taking a close look at $\mathrm{MgAlBO}_{4}$ sinhalite, we can recognize fragments of the parent elemental metal structures, e.g.: the (110) planes of fcc-Al with Al-Al distances of $2.85 \AA$ and $4.33 \AA$ parallel to the $c$ axis (see Fig. $1 \mathrm{~b}$ ), which can be compared with the $2.86 \AA \mathrm{Al}-\mathrm{Al}$ 
distance and the $4.05 \AA$ lattice parameter in elemental aluminium. This fact has been reported for several oxides with $\mathrm{Al}$ atoms in octahedral coordination ${ }^{37}$. For instance, the $\mathrm{Al}$ sublattice of $\mathrm{Al}_{2} \mathrm{BeO}_{4}$ chrysoberyl also reproduce large fragments of the fcc-Al structure and the mean value for the Al-Al distance is also $2.85 \AA$ at room conditions.

Some relationships can also be inferred after comparing the six olivine isomorphs with different cation valences and sizes collected in Table 3. Firstly, the zero-pressure unit-cell volumes of silicates at room pressure are considerably larger than those of $\mathrm{MgAlBO}_{4}$ sinhalite and $\mathrm{Al}_{2} \mathrm{BeO}_{4}$ chrysoberyl due to the smaller size of the $\mathrm{B}$ and $\mathrm{Be}$ atoms compared to the $\mathrm{Si}$ atoms. Moreover, the existence of these tetrahedral atoms entails that the trivalent $\mathrm{Al}^{3+}$ cations ocuppy one or two octahedral sites. Note that $\mathrm{AlO}_{6}$ octaedra are significantly smaller than $\mathrm{MgO}_{6}$ octahedra (Al-O average distance in chrysoberyl: $1.914 \AA$ vs $\mathrm{Mg}-\mathrm{O}$ average distance in forsterite: $2.113 \AA$ ), which accounts for the smallest volume of $\mathrm{Al}_{2} \mathrm{BeO}_{4}$. Secondly, $\mathrm{Al}_{2} \mathrm{BeO}_{4}$ chrysoberyl is $29 \%$ more incompressible than $\mathrm{MgAlBO}_{4}$ sinhalite (see inset of Fig. 4), which in turn is more incompressible than all silicate olivines (e.g. $27 \%$ with respect to $\mathrm{Mg}_{2} \mathrm{SiO}_{4}$ forsterite). Since the tetrahedral units of the olivine structure show generally very little compression, regardless the nature of the $T$ atom (tetrahedra bulk moduli $\geq 300 \mathrm{GPa}$ ), the compressional behaviour of the olivine structure is controlled by octahedral units and the nature of the $M$ cations located in those units. Such behaviour is in sharp contrast to other binary oxide compounds like $\mathrm{MgAl}_{2} \mathrm{O}_{4}$ spinel, in which the observed crystal bulk modulus is the average of tetrahedral and octahedral bulk moduli38.

Our data confirm that, whereas divalent cation octahedra display significant compression with bulk moduli $<150 \mathrm{GPa}$ (for instance, $\mathrm{B}_{\mathrm{Fe}(I) 06}=149 \mathrm{GPa}^{39}$, which is also consistent with the fact that forsterite and fayalite had similar bulk compressibility values ${ }^{31}$ ), $\mathrm{Alll}^{\mathrm{I}} \mathrm{O}_{6}$ octahedra are reported to be considerably more rigid with bulk moduli $>180 \mathrm{GPa}^{28,31,40}$. This inverse relationship between cation formal charge and octahedral compressibility was also previously reported for different spinels 38,41 . Note that in sinhalite, for instance, the compressibility ratio of $\mathrm{MgO}_{6}: \mathrm{AlO}_{6}$ octahedra is close to 2 . The above reasoning explains, on one hand, the relative incompressibility of non-silicate olivines (containing one or two Al atoms in octahedral sites) and, on the other hand, the smaller compressibility of chrysoberyl than of sinhalite (the first compound contains two $\mathrm{Al}$ in its chemical formula while the second one contains one $\mathrm{Al}$ and one $\mathrm{Mg}$ ). Finally, the aforementioned rules can also give some insights on the olivine axial anisotropy under pressure. Sinhalite presents similar a and $c$ axial compressibilities as chrysoberyl (see Table 3), but a larger $b$-axis compressibility. This is directly related to the different stiffness of the $\mathrm{M}(2)$ cation octahedra, $\mathrm{Mg}^{\|} \mathrm{O}_{6}$ and $\mathrm{Alll}^{\prime \prime} \mathrm{O}_{6}$ for $\mathrm{MgAlBO}_{4}$ and $\mathrm{Al}_{2} \mathrm{BeO}_{4}$, respectively. In the same manner, compressional behaviour of silicate olivines can be elucidated 42 . 


\section{B. Possible high pressure phases of sinhalite.}

232 To conclude this experimental and theoretical study of the behaviour of sinhalite under pressure, we want to comment on possible high pressure phases of sinhalite. In this respect, we have calculated the energy-volume curves of potential high-pressure phases for sinhalite on the basis of HP polymorphs of $\mathrm{Mg}_{2} \mathrm{SiO}_{4}$ with structures such as wadsleyite, ringwoodite, $\mathrm{TIAISiO}_{4}$ and thenardite, which can be seen in Fig. 6. As it can be observed, only the wadsleyite-like phase is energetically competitive with the olivine structure at high pressures. Note that the thenardite-like candidate is not depicted due to the large energy difference with respect to the olivine structure. According to our calculations, sinhalite could transform into a wadsleyite-like structure near $83 \mathrm{GPa}$. In this way, sinhalite would follow the same structural sequence as forsterite, either at high-pressure and temperature ${ }^{24}$ or just at high pressure ${ }^{31}$. It should be stressed that the olivine-wadsleyite transition could imply large kinetic barriers since in forsterite the olivine structure at ambient temperature persists at pressures far beyond the thermodynamic stability limit of this mineral phase ${ }^{43}$. Therefore, it is presumable that the wadsleyite-like phase of sinhalite could be observed at ambient temperature at pressures much higher than $83 \mathrm{GPa}$.

The lattice parameters and atomic positions of the theoretically calculated wadsleyite-type structure for $\mathrm{MgAlBO}_{4}$ at $84.7 \mathrm{GPa}$ are collected in Table 4. Our calculations predict a volume collapse of $4.2 \%$ at the phase transition, in comparison with the approx. $7 \%$ experimentally observed in $\mathrm{Mg}_{2} \mathrm{SiO}_{4}$ forsterite. This HP phase would be characterized by $\mathrm{B}_{2} \mathrm{O}_{7}$ groups with a $\mathrm{B}-\mathrm{O}-\mathrm{B}$ angle of approx. $119^{\circ}$, being $\mathrm{Mg}$ and $\mathrm{Al}$ atoms still in octahedral configuration. The zero-pressure volume, bulk modulus and pressure derivative for this phase as obtained from a $3^{\text {rd }}$ order BM EOS are $V_{0}=551.6 \AA^{3}, B_{0}=217.9$ $\mathrm{GPa}$ and $\mathrm{B}_{0}{ }^{\prime}=4.2$, respectively. As expected, the high-pressure phase is considerably more incompressible than the low-pressure $\mathrm{MgAlBO}_{4}$ sinhalite phase and $\mathrm{Mg}_{2} \mathrm{SiO}_{4}$ wadsleyite ${ }^{44}$.

\section{5.- Conclusions}

Rock-forming silicate minerals such as pyroxenes, garnets, olivines and even perovskites are often subject to compositional mixed-valence subtitutions in the cation sublattice offering rich crystal chemistry. $\mathrm{MgAlBO}_{4}$ sinhalite is an olivine-like mineral where the tetrahedrally coordinated $\mathrm{Si}$ atoms and half of the octahedrally coordinated $\mathrm{Mg}$ atoms of $\mathrm{Mg}_{2} \mathrm{SiO}_{4}$ forsterite have been replaced by $\mathrm{B}$ and $\mathrm{Al}$ atoms, respectively. In this work, we report the study of the structural behaviour of $\mathrm{MgAlBO}_{4}$ under pressure, which evidences significant effects of mixed-valence substitution on compression. Thus, the incorporation of $\mathrm{Al}$ atoms into the octahedral sites increases by $27 \%$ the bulk modulus with respect to 
forsterite. The compressibility ratio of $\mathrm{MgO}_{6}: \mathrm{AlO}_{6}$ octahedra with a value close to 2 (Polyhedral bulk moduli obtained from our calculations: $130(1)$ and $250(1) \mathrm{GPa}$ for $\mathrm{MgO}_{6}$ and $\mathrm{AlO}_{6}$, respectively) explains both the higher incompressibility and its anisotropy. Moreover, our calculations suggest that sinhalite could transform into a wadsleyite-type phase above $83 \mathrm{GPa}$.

\section{Acknowledgments}

This study was supported by the Spanish government MEC under Grants No: MAT2010-21270-C0401/03/04, MAT2013-46649-C4-1/2/3-P and CTQ2009-14596-C02-01, by the Comunidad de Madrid and European Social Fund (S2009/PPQ-1551 4161893), by MALTA Consolider Ingenio 2010 project (CSD2007-00045), and by Generalitat Valenciana (GVA-ACOMP-2013-1012 and GVA-ACOMP-2014243). Experiments were performed at MSPD beamline at ALBA Synchrotron Light Facility with the collaboration of ALBA staff. A.M. and P.R-H. acknowledge computing time provided by Red Española de Supercomputación (RES) and MALTA-Cluster. J.A.S. acknowledges financial support through the Juan de la Cierva fellowship. We are particularly grateful to Angel Vegas for stimulating discussions and critical reading of this manuscript.

\section{References}

[1] Claringbull, G.F.; Hey, M.H. Sinhalite (MgAlBO 4$)$, a new mineral. Mineral. Mag. 1952, 29, 841-849.

[2] Fang, J.H.; Newnham, R.E. The crystal structure of sinhalite. Mineral. Mag. 1965, 35, 196-199.

[3] Capponi, J.J.; Chenavas, J.; Joubert, J.C. Synthese hydrothermale a tres haute pression de deux borates de type olivine, $\mathrm{AlMgBO}_{4}$ et FeNiBO4. Mat. Res. Bull. 1973, 8, 275-281.

[4] Hayward, C.L.; Angel, R.J.; Ross, N.L. The structural redetermination and crystal chemistry of sinhalite, $\mathrm{MgAlBO}_{4}$. Eur. J. Mineral. 1994, 6, 313-321.

[5] Hyde, B.G.; White, T.J.; O'Keeffe, M.; Johnson, A.W.S. Structures related to those of spinel and the beta-phase, and a possible mechanism for the transformation olivine-spinel. Z. Kristallogr. 1982, 160, 53-62.

[6] Vegas, A. Concurrent pathways in the phase transitions of alloys and oxides: Towards a unified vision of inorganic solids. Struct. Bond. 2011, 138, 133-198.

[7] Vegas, A.; Jansen, M. Structural relationships between cations and alloys: An equivalence between oxidation and pressure. Acta Cryst. B 2002, 58, 38-51.

[8] Santamaria-Perez, D.; Vegas, A.; Liebau, F. The Zintl-Klemm concept applied to cations in oxides. II. The structure of silicates. Struct. Bond. 2005, 118, 121-177.

[9] Vegas, A.; Mattesini, M. Towards a generalized visión of oxides: Disclosing the role of cations and anions in determining unit-cell dimensions. Acta Cryst. B 2010, 66, 338-344. 
298 [11] Santamaria-Perez, D.; Gomis, O.; Sans, J.A.; Ortiz, H.M.; Vegas, A.; Errandonea, D.; Ruiz-Fuertes, J.; Martinez-Garcia, D.; Garcia-Domene, B.; Pereira, A.L.J., et al. Compressibility systematics of calcitetype borates: An experimental and theoretical structural study of $\mathrm{ABO}_{3}(\mathrm{~A}=\mathrm{Al}, \mathrm{Sc}, \mathrm{Fe}$ and In). J. Phys. Chem. C 2014, 118, 4354-4361.

[12] Yang, H.; Downs, R.T.; Finger, L.W.; Hazen, R.M.; Prewitt, C.T. Compressibility and crystal structure of kyanite, Al2SiO5, at high pressure. Amer. Mineral. 1997, 82, 467-474.

[13] Werding, G.; Alsumady, K.; Schreyer, W.; Medenbach, O. Low-pressure synthesis, physical properties, miscibility and preliminary stability of sinhalite $\mathrm{MgAIBO}_{4}$. Neues Jarh. Mineral. Abh. 1981, $141,201-216$.

[14] Fauth, F.; Peral, I.; Popescu, C.; Knapp, M. The New Material Science Powder Diffraction Beamline at ALBA Synchrotron. Powd. Diffract. 2013, 28, S360-S370.

[15] Mao, H.K.; Xu, J.;Bell, P.M. Calibration of the Ruby Pressure Gauge to 800-Kbar under QuasiHydrostatic Conditions. J. Geophys. Res. 1986, 91, 4673-4676.

[16] Errandonea, D.; Boehler, R.; Japel, S.; Mezouar, M.; Benedetti, L.R. Structural transformation of compressed solid Ar: An x-ray diffraction study to 114 GPa. Phys. Rev. B 2006, 73, 092106.

[17] Hammersley, A.P.; Svensson, S.O.; Hanfland, M.; Fitch, A.N.; Hausermann, D. Two-Dimensional Detector Software: From Real Detector to Idealized Image or Two-Theta Scan. High Press. Res. 1996, 14, 235-248.

[18] Rodriguez-Carvajal, J. Recent Advances in Magnetic-Structure Determination by Neutron Powder Diffraction. Physica B 1993, 192, 55-69.

[19] Nolze, G.; Kraus, W. Powdercell 2.0 for Windows. Powd. Diffract. 1998, 13, 256-259.

[20] Kresse, G.; Furthmuller, J. Efficient Iterative Schemes for Ab Initio Total-Energy Calculations using a Plane-Wave Basis Set. Phys. Rev. B 1996, 54, 11169-11186.

[21] Kresse, G.; Joubert, D. From Ultrasoft Pseudopotentials to the Projector Augmented-Wave Method. Phys. Rev. B 1999, 59, 1758-1775.

[22] Perdew, J.P.; Ruzsinszky, A.; Csonka, G.I.; Vydrov, O.A.; Scuseria, G.E.; Constantin, L.A.; Zhou, X.L.; Burke, K. Restoring the Density-Gradient Expansion for Exchange in Solids and Surfaces. Phys. Rev. Lett. 2008, 100, 136406.

[23] Blochl, P.E. Projector Augmented-Wave Method. Phys. Rev. B 1994, 50, 17953-17979.

[24] Katsura, T.; Ito, E. The system $\mathrm{Mg}_{2} \mathrm{SiO}_{4}-\mathrm{Fe}_{2} \mathrm{SiO}_{4}$ at high pressures and temperatures: Precise determination of stabilities of olivine, modified-spinel and spinel. J. Geophys. Res. 1989, 94, 1566315670.

330 [25] Santamaria-Perez, D.; Amboage, M.; Manjón, F.J.; Errandonea, D.; Muñoz, A.; Rodriguez-

331 Hernandez, P.; Mujica, A.; Radescu, S.; Ursaki, V.V.; Tiginyanu, I.M. Crystal Chemistry of $\mathrm{Cd}_{2} \mathrm{n}_{2} \mathrm{~S}_{4}$, $332 \mathrm{Mgln}_{2} \mathrm{~S}_{4}$ and $\mathrm{MnIn}_{2} \mathrm{~S}_{4}$ Thiospinels under High Pressure. J. Phys. Chem. C 2012, 116, 14078-14087. 
[26] Mujica, A.; Rubio, A.; Muñoz, A.; Needs, R.J. High-pressure phases of the group-IV, III-V, and II-VI compounds. Rev. Mod. Phys. 2003, 75, 863-912.

[27] Birch, F. Finite Strain Isotherm and Velocities for Single Crystal and Polycrystalline $\mathrm{NaCl}$ at HighPressures and 300 Degrees K. J. Geophys. Res. 1978, 83, 1257-1268.

[28] Robinson, K.; Gibbs, G.V.; Ribbe, P.H. Quadratic elongation: A quantitative measure of distortion in coordination polyhedra. Science 1971, 172, 567-570.

[29] Downs, R.T.; Zha, C-S.; Duffy, T.S.; Finger, L.W. The equation of state of forsterite to $17.2 \mathrm{GPa}$ and effects of pressure media. Amer. Mineral. 1996, 81, 51-55.

[30] Sharp, Z.D.; Hazen, R.M.; Finger, L.W. High-pressure crystal chemistry of monticellite, $\mathrm{CaMgSiO}_{4}$. Amer. Mineral. 1987, 72, 748-755.

[31] Andrault, D.; Bouhifd, M.A.; Itie, J.P.; Richet, P. Compression and amorphization of $(\mathrm{Mg}, \mathrm{Fe})_{2} \mathrm{SiO}_{4}$ olivines: An x-ray diffraction study up to 70 GPa. Phys. Chem. Miner. 1995, 22, 99-107.

[32] Hazen, R.M.; Downs, R.T.; Finger, L.W. High-pressure crystal chemistry of $\mathrm{LiScSiO}_{4}$ : An olivine with nearly isotropic compression. Amer. Mineral. 1996, 81, 327-334.

[33] Hazen, R.M. High-pressure crystal chemistry of chrysoberyl, $\mathrm{Al}_{2} \mathrm{BeO}_{4}$ : Insights on the origin of olivine elastic anisotropy. Phys. Chem. Miner. 1987, 14, 13-20.

[34] Sung, C.M.; Burns, R.G. Crystal structure features of the olivine - spinel transition. Phys. Chem. Miner. 1978, 2, 177-197.

[35] Brown, G.E. Olivine and silicate spinels. 1980. In P.H. Ribbe, Ed., Reviews in Mineralogy, Vol. 5, Orthosilicates, p. 275-381. Mineralogical Society of America, Washington, D.C.

[36] Lumpkin, G.R.; Ribbe, P.H. Composition, order-disorder and lattice parameters of olivines: Relationships in silicate, germanate, beryllate, phosphate and borate olivines. Amer. Miner. 1983, 68, 164-176.

[37] Vegas, A. Cations in inorganic solids. Cryst. Rev. 2000, 7, 189-283.

[38] Finger, L.W.; Hazen, R.M.; Hofmeister, A.M. High-pressure crystal chemistry of spinel (MgAl2O4) and magnetite (Fe3O4). Comparisons with silicate spinels. Phys. Chem. Miner. 1986, 13, 215-220.

[39] Zhang, L.; Ahsbahs, H.; Hafner, S:S:; Kutoglu, A. Single-crystal compression and crystal structure of clinopyroxene up to $10 \mathrm{GPa}$, Amer. Mineral. 1997, 82, 245-258.

[40] Wentzcovitch, R.M.; Stixrude, L. Crystal chemistry of forsterite: A first-principles study. Amer. Mineral. 1997, 82, 663-671.

[41] Recio, J.M.; Franco, R.; Martin-Pendas, A.; Blanco, M.A.; Pueyo, L; Pandey, R. Theoretical explanation of the uniform compressibility behavior observed in oxide spinels. Phys. Rev. B. 2001, 63, 184101.

[42] Smyth, J.R.; Jacobsen, S.D.; Hazen, R.M. Comparative crystal chemistry of orthosilicate minerals. Rev. Mineral. 2000, 41, 187-210.

[43] Sung, C.M.; Burns, R.G. Kinetics of the olivine-spinel transition: Inplications to deep-focus earthquakes genesis. Earth Planet. Sci. Lett. 1976, 32, 165-170. 
370 [44] Kiefer, B.; Stixrude, L.; Hafner, J.; Kresse, G. Structure and elasticity of wadsleyite at high 371 pressures. Amer. Mineral. 2001, 86, 1387-1395.

372 
Table 1.- Positional parameters for sinhalite in SG Pbnm. Experimental values reported by Hayward et 379 al. from single-crystal XRD measurements ${ }^{4}$ and our theoretical calculated data are in excellent 380 agreement at room conditions.

381

\begin{tabular}{|c|c|c|c|c|c|c|}
\hline & \multicolumn{3}{|c|}{ Experimental atomic positions ${ }^{4}$} & \multicolumn{3}{|c|}{ Theoretical atomic positions (This study) } \\
\hline Site & $x$ & $y$ & $z$ & $x$ & $y$ & $Z$ \\
\hline $\mathrm{Al}$ & 0 & 0 & 0 & 0 & 0 & 0 \\
\hline $\mathrm{Mg}$ & $0.98532(10)$ & $0.27606(4)$ & $1 / 4$ & 0.98481 & 0.27528 & $1 / 4$ \\
\hline $\mathrm{B}$ & $0.4085(3)$ & $0.0874(1)$ & $1 / 4$ & 0.40871 & 0.08634 & $1 / 4$ \\
\hline 01 & $0.7410(2)$ & $0.08063(9)$ & $1 / 4$ & 0.74167 & 0.08039 & $1 / 4$ \\
\hline 02 & $0.2566(2)$ & $0.44414(9)$ & $1 / 4$ & 0.25501 & 0.44397 & $1 / 4$ \\
\hline 03 & $0.2647(1)$ & $0.14876(6)$ & $0.0385(1)$ & 0.26499 & 0.14873 & 0.03842 \\
\hline
\end{tabular}


384 Table 2.- Sinhalite polyhedral volumes, distortion parameters and average cation-anion bond distances $385(\mathrm{ABD})$ at various pressures. QE and $\mathrm{AV}$ denote quadratic elongation and bond angle variance in the 386 different polyhedra as defined in Robinson et al. ${ }^{28}$, respectively.

\begin{tabular}{|c|c|c|c|c|c|}
\hline Atom/Parameter & $1 \cdot 10^{-4} \mathrm{GPa}$ & $5.7 \mathrm{GPa}$ & $12.9 \mathrm{GPa}$ & $19.1 \mathrm{GPa}$ & $26.3 \mathrm{GPa}$ \\
\hline \multicolumn{6}{|l|}{$M(1)$ site $-A l$} \\
\hline $\mathrm{V}\left(\AA^{3}\right)$ & 8.945 & 8.744 & 8.526 & 8.358 & 8.186 \\
\hline QE & 1.0200 & 1.0191 & 1.0181 & 1.0174 & 1.0166 \\
\hline $\operatorname{AV}\left({ }^{\circ} 2\right)$ & 67.55 & 64.90 & 62.02 & 59.66 & 57.41 \\
\hline $\mathrm{ABD}(\AA)$ & 1.904 & 1.889 & 1.872 & 1.859 & 1.846 \\
\hline \multicolumn{6}{|l|}{$M(2)$ site $-M g$} \\
\hline $\mathrm{V}\left(\AA^{3}\right)$ & 11.597 & 11.144 & 10.671 & 10.326 & 9.984 \\
\hline QE & 1.0350 & 1.0328 & 1.0305 & 1.0290 & 1.0275 \\
\hline $\mathrm{AV}\left({ }^{\circ} 2\right)$ & 123.05 & 114.92 & 106.82 & 101.08 & 95.78 \\
\hline $\operatorname{ABD}(\AA)$ & 2.091 & 2.062 & 2.030 & 2.006 & 1.982 \\
\hline \multicolumn{6}{|l|}{ T site $-B$} \\
\hline $\mathrm{V}\left(\AA^{3}\right)$ & 1.700 & 1.676 & 1.649 & 1.627 & 1.605 \\
\hline QE & 1.0125 & 1.0122 & 1.0119 & 1.0117 & 1.0115 \\
\hline $\mathrm{AV}\left({ }^{\circ} 2\right)$ & 53.73 & 52.63 & 51.33 & 50.50 & 49.71 \\
\hline $\mathrm{ABD}(\AA)$ & 1.499 & 1.492 & 1.484 & 1.477 & 1.470 \\
\hline
\end{tabular}


390 Table 3.- Zero-pressure volumes $\left(V_{0}, \AA^{3}\right)$, bulk moduli $\left(B_{0}, \mathrm{GPa}\right)$, first-pressure derivatives $\left(B^{\prime}\right)$, axial 391 compressibilities $\left(\beta_{x} \cdot 10^{-3} \mathrm{GPa}^{-1}\right.$ ) and axial compression ratios (defined as $\beta_{a}{ }^{\text {rat }}=\beta_{a} / \beta_{a}, \beta_{b}{ }^{\text {rat }}=\beta_{b} / \beta_{a}$, and $392 \beta_{c}{ }^{\text {rat }}=\beta_{c}\left(\beta_{a}\right)$ for different olivine-type compounds.

393

\begin{tabular}{|c|c|c|c|c|c|c|c|c|c|c|c|}
\hline Compound & $\begin{array}{l}\text { Mineral } \\
\text { name }\end{array}$ & $V_{0}$ & $\mathrm{~B}_{0}$ & $B_{0}^{\prime}$ & $\beta_{a}$ & $\beta_{b}$ & $\beta_{c}$ & $\beta_{a^{\text {rat }}}$ & $\beta_{b}{ }^{r a t}$ & $\beta_{c}{ }^{r a t}$ & Ref. \\
\hline $\mathrm{Mg}_{2} \mathrm{SiO}_{4}$ & Forsterite & 290.1(1) & $125(2)$ & $4.0(4)$ & 1.35 & 2.70 & 2.10 & 1.00 & 1.99 & 1.55 & [29] \\
\hline $\mathrm{CaMgSiO}_{4}$ & Monticellite & $341.6(1)$ & 113(1) & 4 (fixed) & 1.96 & 3.62 & 2.05 & 1.00 & 1.85 & 1.05 & [30] \\
\hline $\mathrm{Fe}_{2} \mathrm{SiO}_{4}$ & Fayalite & 307.2 & $125(5)$ & 4 (fixed) & 1.5 & 3.8 & 2.2 & 1.00 & 2.53 & 1.47 & [31] \\
\hline $\mathrm{LiScSiO}_{4}$ & - & $299.7(1)$ & 118(1) & 4 (fixed) & 2.70 & 2.80 & 2.61 & 1.00 & 1.04 & 0.97 & [32] \\
\hline $\mathrm{Al}_{2} \mathrm{BeO}_{4}$ & Chrisoberyl & $228.5(1)$ & $242(5)$ & 4 (fixed) & 1.12 & 1.46 & 1.31 & 1.00 & 1.30 & 1.17 & [33] \\
\hline $\mathrm{MgAlBO}_{4}$ & Sinhalite & $\begin{array}{l}242.8(1) \\
242.7(1)\end{array}$ & $\begin{array}{l}171(3) \\
173(1)\end{array}$ & $\begin{array}{l}4.2(3) \\
4(\text { fixed) }\end{array}$ & 1.06 & 2.17 & 1.30 & 1.00 & 2.05 & 1.23 & $\begin{array}{l}\text { This } \\
\text { study }\end{array}$ \\
\hline
\end{tabular}

394 
399 Table 4.- Theoretically calculated positional parameters for the Imma wadsleyite-type phase at 84.7 400 GPa. Lattice parameters are $a=5.03952 \AA, b=9.80813 \AA$ and $c=7.20236 \AA(Z=8)$.

401

\begin{tabular}{|c|c|c|c|c|}
\hline Atoms & Sites & $\boldsymbol{x}$ & $\boldsymbol{y}$ & $\boldsymbol{z}$ \\
\hline $\mathrm{Al}$ & $8 \mathrm{~g}$ & $1 / 4$ & 0.38279 & $1 / 4$ \\
\hline $\mathrm{Mg} 1$ & $4 \mathrm{~b}$ & 0 & 0 & 0.5 \\
\hline $\mathrm{Mg} 2$ & $4 \mathrm{e}$ & 0 & $1 / 4$ & 0.55131 \\
\hline $\mathrm{B}$ & $8 \mathrm{~h}$ & 0 & 0.37407 & 0.89598 \\
\hline $\mathrm{O} 1$ & $4 \mathrm{e}$ & 0 & $1 / 4$ & 0.26921 \\
\hline O2 & $4 \mathrm{e}$ & 0 & $1 / 4$ & 0.79706 \\
\hline 03 & $8 \mathrm{~h}$ & 0 & 0.48701 & 0.75953 \\
\hline O4 & $16 \mathrm{j}$ & 0.27033 & 0.37578 & 0.49272 \\
\hline
\end{tabular}

402

403

404

405

406 
Figure captions

410

411 Figure 1.- (a), (b), (c) Projection of the $\mathrm{MgAlBO}_{4}$ sinhalite structure down the $\mathrm{a}, \mathrm{b}$ and $\mathrm{c}$ axes, 412 respectively, which show the $M(1), M(2)$ and $T$ polyhedral connectivity mentioned in the text. (d) The distorted $\mathrm{Ni}_{2}$ In-type structure of the cation MgAIB subarray in sinhalite. This projection along the a axis shows the trigonal faces of the trigonal prisms considered to be major features of this structure. $\mathrm{Mg}, \mathrm{Al}$, $\mathrm{B}$ and $\mathrm{O}$ atoms are denoted as orange, gray, green and red solid spheres.

Figure 2.- $\mathrm{XRD}$ patterns at selected pressures using a mixture $\mathrm{MeOH}: \mathrm{EtOH}$ as pressure transmitting medium.

Figure 3.- Evolution of the lattice parameters of sinhalite under high pressure. Two experimental runs were carried out: Black solid and empty symbols denote upstroke and downstroke, respectively, of that performed with the mixture methanol-ethanol as pressure transmitting medium, whereas the red solid symbols are upstroke data obtained using $\mathrm{Ne}$ as pressure transmitting medium. Triangles, squares and circles correspond to $a, b / 2$ and $c$ axes, respectively. Theoretical calculated data are represented as a solid blue line.

Figure 4.- Unit-cell volume-pressure data of $\mathrm{MgAlBO}_{4}$ sinhalite. Same colour code as in Figure 2. Inset: Normalized unit-cell volumes of different olivines as a function of pressure for the sake of comparison. 429 Black, red, blue, magenta and green lines represent $\mathrm{MgAlBO}_{4}$ (this experimental study), $\mathrm{Al}_{2} \mathrm{BeO}_{4}{ }^{33}$, $430(\mathrm{Mg}, \mathrm{Fe})_{2} \mathrm{SiO}_{4}{ }^{29,31}, \mathrm{LiScSiO}_{4}{ }^{32}$ and $\mathrm{CaMgSiO}_{4}{ }^{30}$, respectively.

Figure 5.- Normalized polyhedral volumes of sinhalite as a function of pressure.

Figure 6.- Energy as a function of volume per formula unit for the initial Pbnm sinhalite structure and the simulated Imma wadsleyite, $\mathrm{Fd}-3 \mathrm{~m}$ ringwwodite (subgroup Imma), $P 2_{1} / \mathrm{n} \mathrm{TIAISiO}$, and Fddd thenardite (subgroup F222) phases. Only the wadsleyite-type phase is energetically competitive with sinhalite below $1 \mathrm{Mbar}$, being thermodynamically more stable at $82.7 \mathrm{GPa}$. 

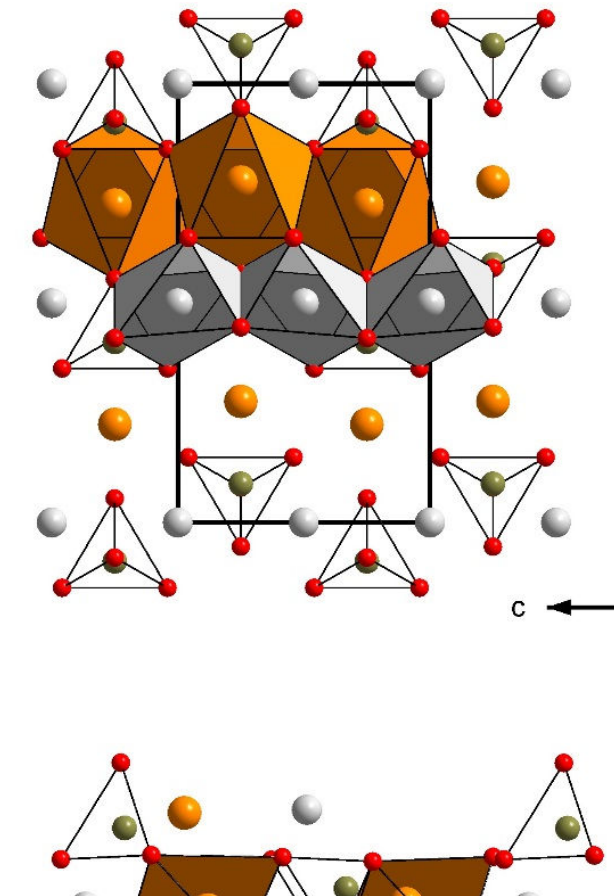


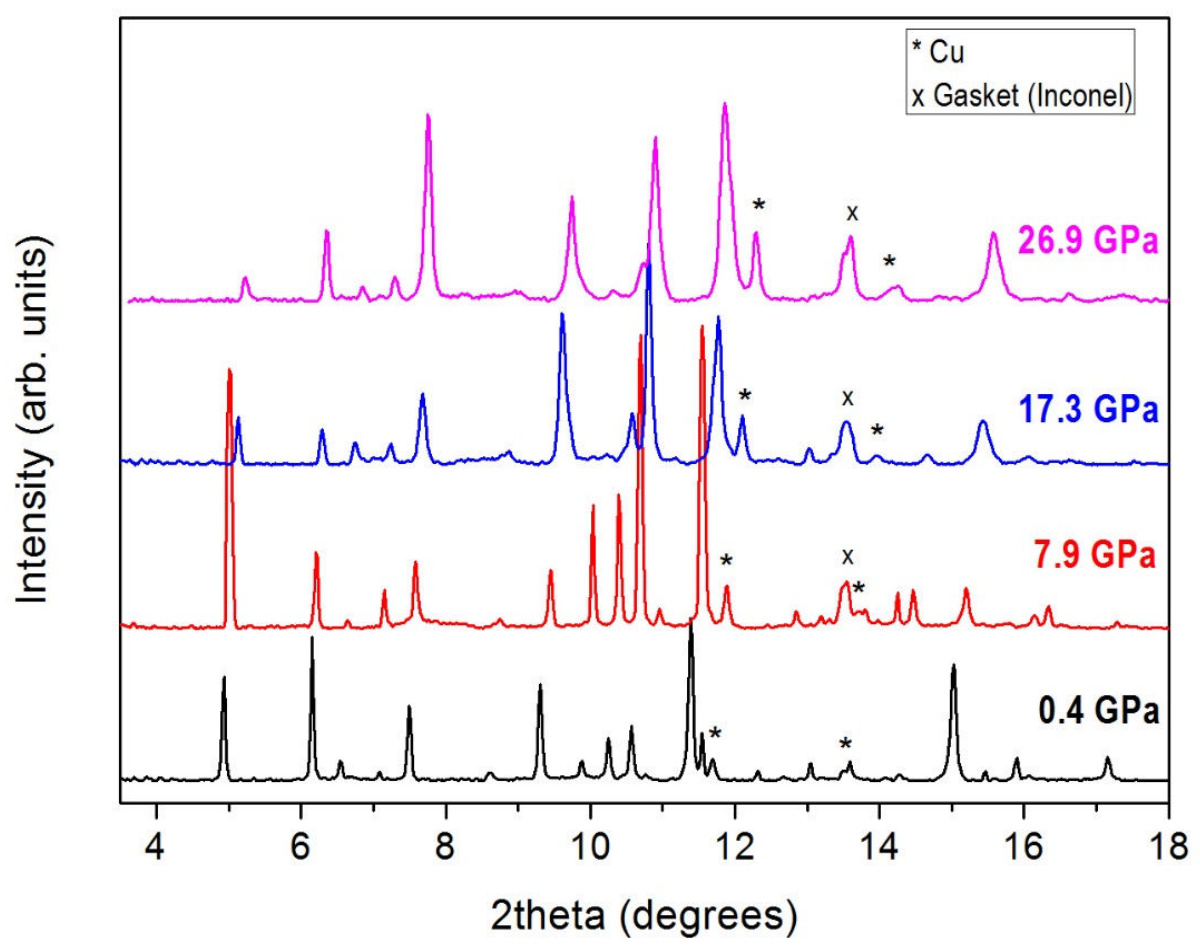

466

467

468

469

470

471

472

Figure 2

473

474 


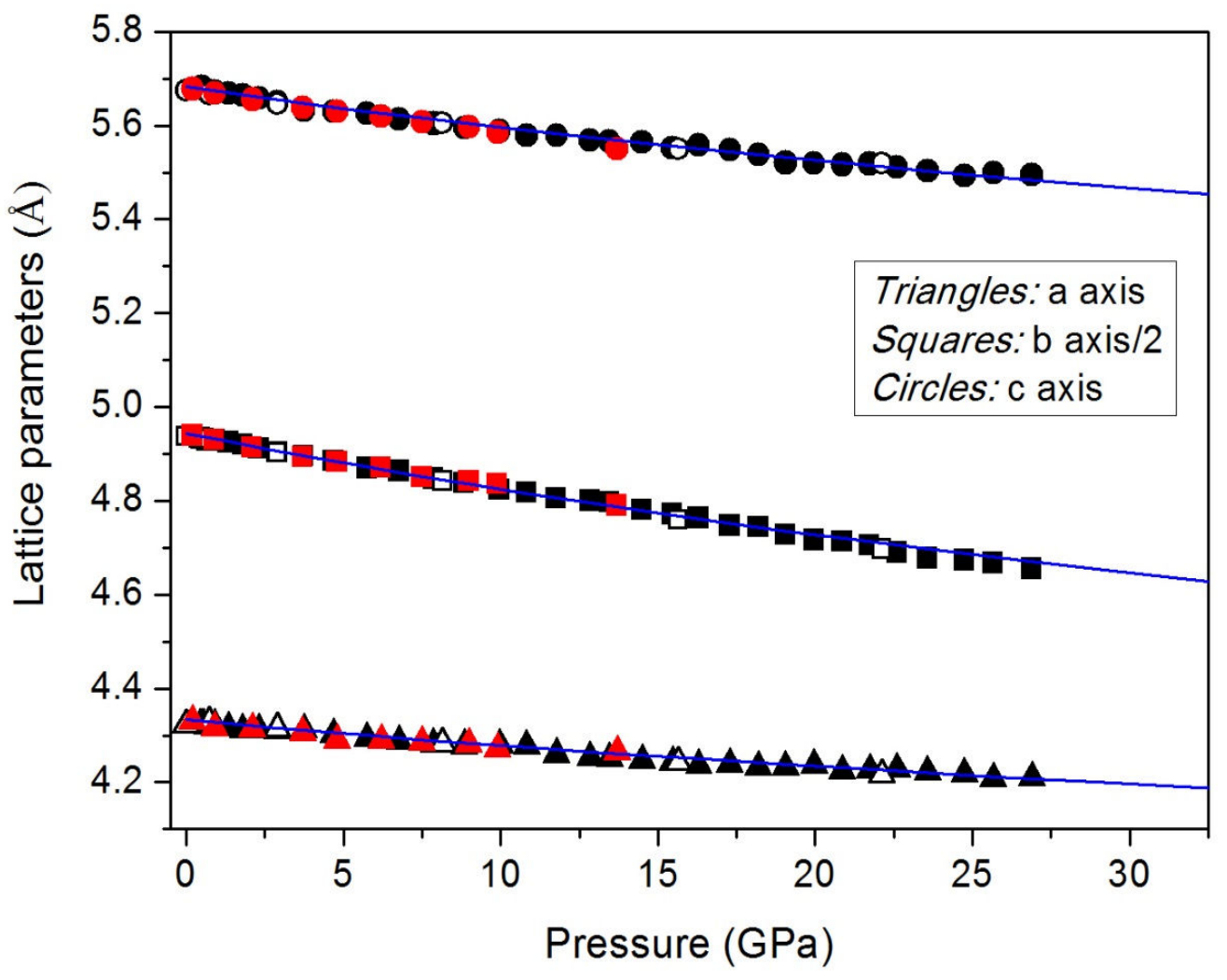

475
476

477

478

479

480

Figure 3

481

482

483 


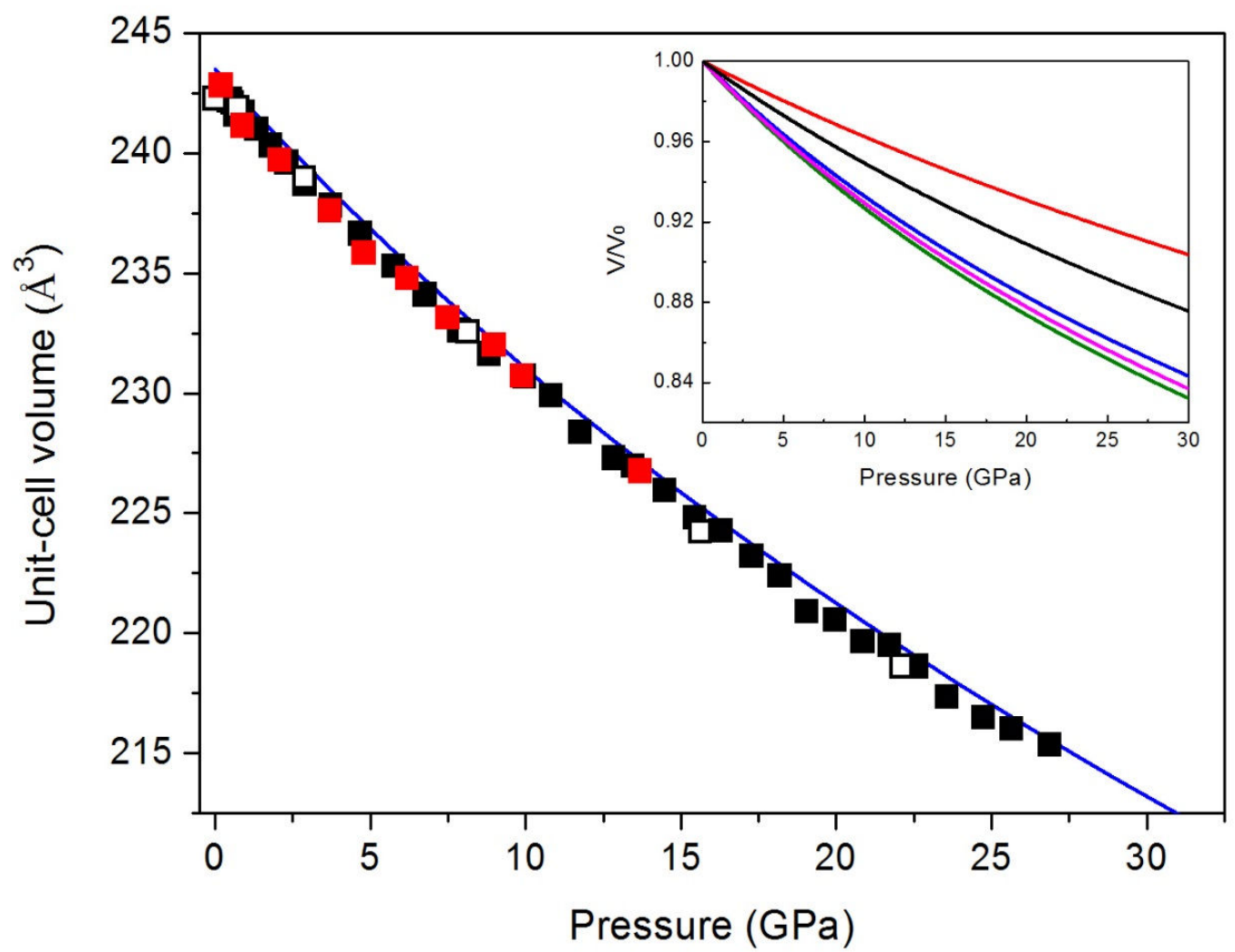

487

488

489

490

491

492

Figure 4

493

494 


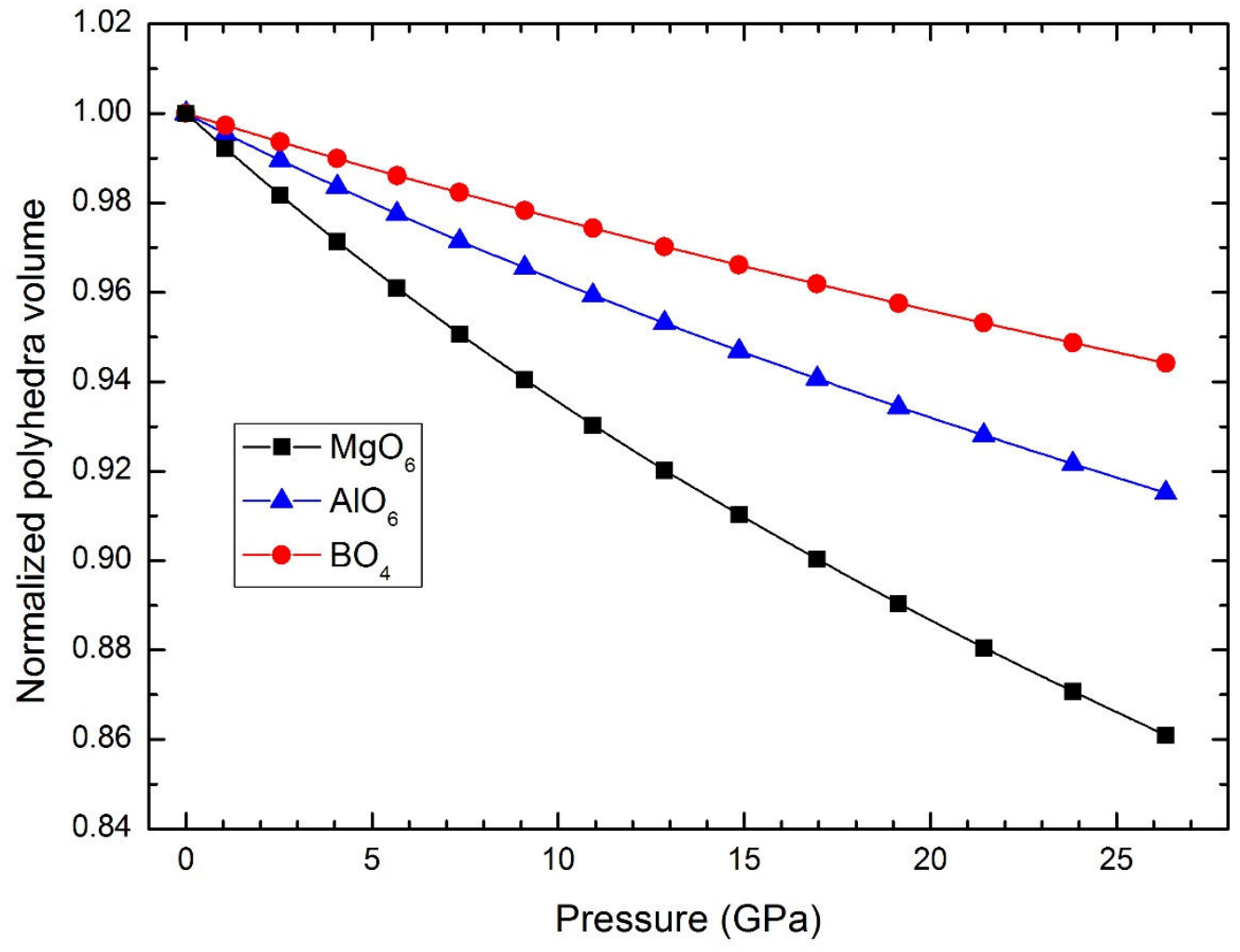

Figure 5

507

508

509 


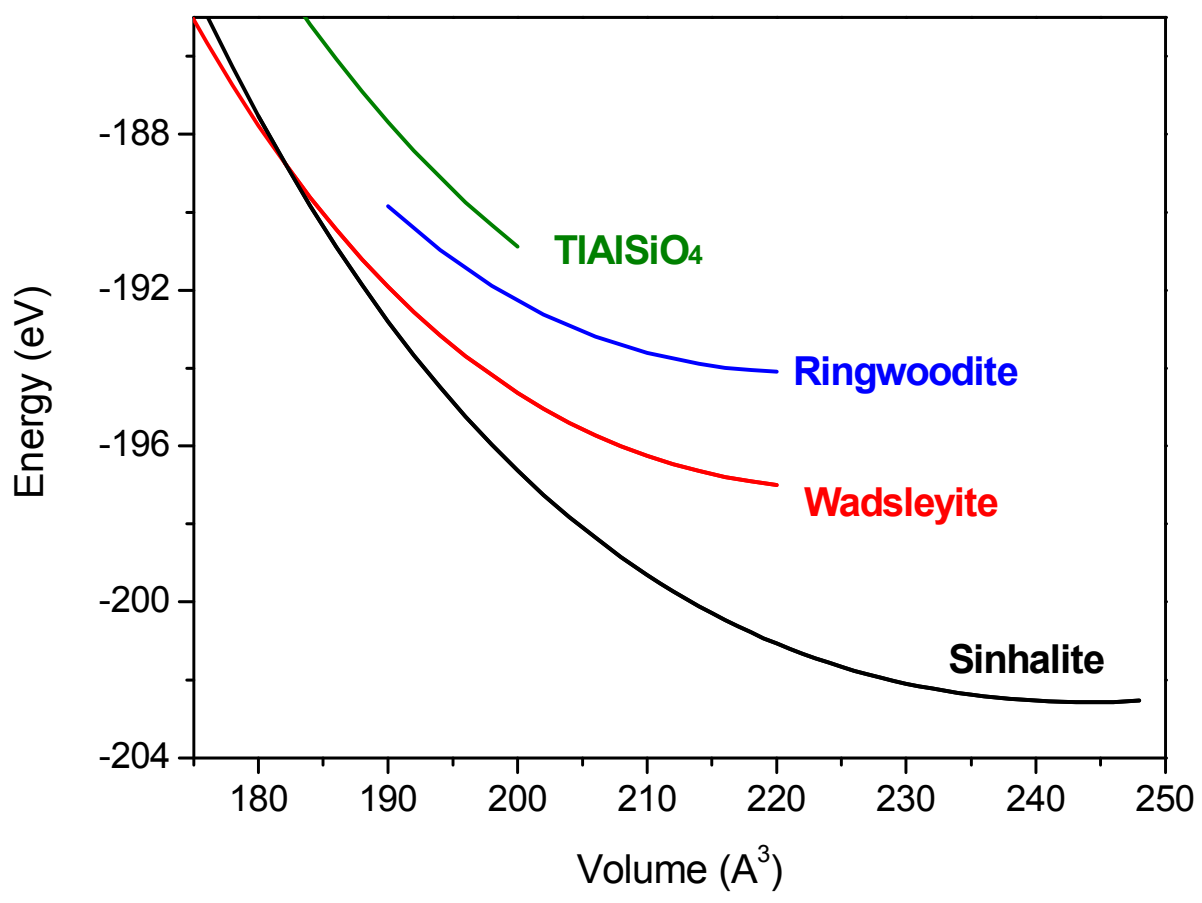

Figure 6 


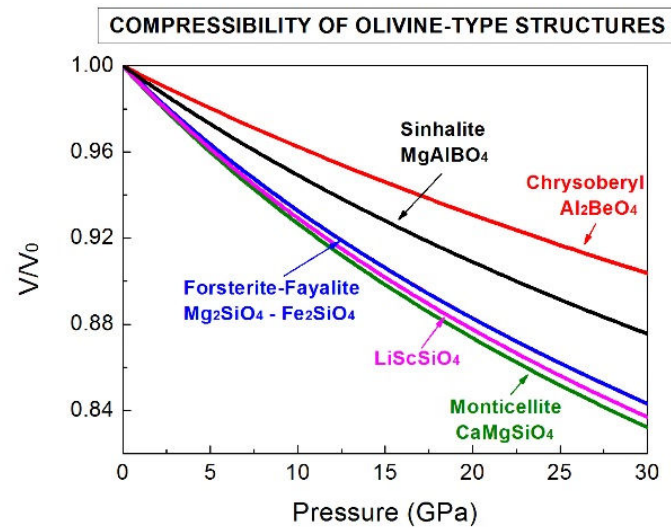

533

534 